\title{
INFORMAÇÃO GEOGRÁFICA PARA O DESENVOLVIMENTO SUSTENTÁVEL EM ÁFRICA
}

\author{
Cristina Delgado Henriques ${ }^{1}$
}

Down to Earth ${ }^{2}$. Este sugestivo título reúne um contributo do Departamento de Estado dos Estados Unidos da América para a cimeira mundial sobre desenvolvimento sustentável, que decorreu em Joanesburgo, em Agosto de 2002. Neste trabalho, apologista do uso dos dados de observação da terra e dos Sistemas de Informação Geográfica, no cumprimento da Agenda 21 em África, valoriza-se a aplicabilidade dos dados geográficos no âmbito do desenvolvimento sustentável. Os autores referem-no como tendo sido concebido para difundir e avaliar a utilidade da informação geográfica nas tomadas de decisão técnicas e políticas.

Nesta perspectiva, para além de relatar algumas experiências levadas a cabo em três regiões da África Sub-Sahariana (norte da bacia do Niger, costa Tanzânia-Quénia e Grandes Lagos, bacias do Limpopo e Zambeze), esta obra procura examinar a forma como as novas tecnologias podem constituir instrumentos de produção de dados geográficos e como a sua utilização pode providenciar um suporte credível aos decisores envolvidos no desenvolvimento sustentável deste Continente.

O estudo inicia-se com o seu enquadramento na Agenda 21 e com o relato de algumas actividades relacionadas com informação geográfica nas regiões africanas acima referidas.

Destacam-se, em seguida, três partes fundamentais. A primeira, abordada no capítulo 4, salienta os aspectos relativos às infra-estruturas dos dados espaciais e dá ênfase ao estado actual e às tendências de alteração das infra-estruturas de telecomunicação em África, uma vez que estas últimas constituem veículos necessários ao progresso da utilização desses dados. A segunda parte incide na descrição dos dados cartográficos de base (desde os pontos de controlo para a geodesia, até à altimetria, à batimetria e à hidrografia) quer dos temáticos (como as redes de transporte, cadastro, ocupação e uso do solo, população), bem como nas ferramentas para os colocar ao serviço do desenvolvimento sustentável (capítulos 5, 6 e 7). Nestes capítulos são abordadas as fontes de dados, a sua disponibilidade, a adequação ao caso africano, a capacidade de actualização e o custo. Dão-se exemplos de aplicação e integração de dados temáticos, nomeadamente

1 Assistente da Faculdade de Arquitectura da Universidade Técnica de Lisboa, Rua Prof. Cid dos Santos, Pólo Universitário, Alto da Ajuda, 1349-055 Lisboa, Portugal. E-mail: cdh@fa.utl.pt http://cartografia.fa.utl.pt

2 National Research Council of the National Academies (2002) - Down to Earth. Geographical Information for Sustainable Development in Africa. The National Academic Press. Washington D.C., $155 \mathrm{p}$. 
os provenientes da Detecção Remota, e sublinha-se o papel dos Sistemas de Informação Geográfica quer na modelação desses dados, quer como instrumentos de apoio à decisão. A terceira parte (capítulo 8) realça alguns aspectos relacionados com a existência da capacidade real de utilização dos dados geográficos por parte das diferentes organizações nos países africanos (administração, universidades, empresas) necessária ao desenvolvimento sustentável. Ou seja, defende-se que é necessário que cada país disponha de recursos humanos com formação adequada para lidar com as diferentes dimensões da informação geográfica (aquisição, armazenamento e gestão de dados; análise espacial e modelação geográfica), por forma a assegurar a continuidade na aquisição e transmissão desses conhecimentos; que se incentive o esforço para que seja dado às organizações nacionais, designadamente às universidades, o enquadramento necessário para promover a formação e a aplicação dos conhecimentos; que se aposte na cooperação entre os vários sectores da sociedade (governo, sociedade civil e sector privado) para se concertarem estratégias comuns de desenvolvimento de actividades relevantes nesta área.

No capítulo final (capítulo 9) fazem-se recomendações e destacam-se as lições aprendidas nas experiências relatadas. Por exemplo, reconhece-se que os problemas que se encontram na intersecção da agricultura com a gestão do ambiente, com as alterações climáticas e com o uso e ocupação do solo, estão na linha da frente das questões do século XXI. Sugerem, então, que as tecnologias de informação geográfica, pela possibilidade de integração de diversos tipos de dados podem criar novas oportunidades de colaboração entre os vários especialistas, como mostram os projectos Miombo Network, LEWS ${ }^{3}$, MARA $^{4}$, entre outros.

Quem concebe projectos para África - com vista ao desenvolvimento sustentável e que envolvam a utilização de dados geográficos - encontra neste trabalho um valioso conjunto de pistas e recomendações que, apesar de genéricas, são pertinentes e muito actuais. Fazem-se referências detalhadas às instituições internacionais (essencialmente americanas ou relacionadas com as Nações Unidas) envolvidas na obtenção de dados e produção de informação geográfica, apresentam-se quadros síntese sobre projectos em curso e sobre a disponibilidade de dados geográficos, encontram-se ao longo de todo o trabalho caixas de texto onde são explicados conceitos ou se faz o enquadramento de determinado tópico. Pena é que não exista um índice para estes quadros e caixas de texto!

A estrutura do texto, as lições aprendidas, as recomendações divulgadas, as referidas caixas de texto, os anexos, os quadros síntese e as figuras com resultados dos estudos têm um cariz extremamente pedagógico para os interessados nas políticas e aplicações da informação geográfica ao desenvolvimento sustentável, mas com poucos conhecimentos técnicos. Para os especialistas nas áreas da informação geográfica, esta estrutura permite tornar o texto mais pragmático, evitando intercalar parágrafos de explicações básicas sem, contudo, perder o sentido dos conceitos utilizados.

O crescimento populacional muito acentuado e, consequentemente, a elevada taxa de transformação do uso do solo, são problemas de grande importância em África, pelas repercussões humanas e ambientais. Para promover o desenvolvimento urbano sustentável e melhorar a qualidade de vida das populações, os responsáveis pelo planeamento e gestão das cidades necessitam de uma visão integrada da paisagem. Assim, também pensamos que o acesso fácil a informação variada, actualizada e facilmente acessível se torna indispensável para compreender os referidos problemas. Por outro lado, os meios

3 Livestock Early Warning System.

${ }_{4}$ Mapping Malaria Risk in Africa. 
técnicos, e nomeadamente os Sistemas de Informação Geográfica, são fundamentais para permitir a análise dessa informação urbana e para a simulação de cenários alternativos.

Embora o documento saliente a importância que a Agenda 21 dá às questões urbanas e suburbanas e refira as dificuldades que existem na obtenção de dados para estas escalas, os exemplos de aplicação apresentados dizem respeito, essencialmente, a escalas de carácter regional. Apontam, contudo, algumas formas de ultrapassar essas dificuldades, baseadas em exemplos levados a cabo nos Estados Unidos, mas faltam exemplos de projectos e formas concretas de ultrapassar as dificuldades na aquisição de informação geográfica urbana. Paralelamente, apresentam uma tabela onde destacam várias questões de índole urbana e suburbana (uso e ocupação do solo, cadastro, infra-estruturas, características socioeconómicas, etc.) com a referência da resolução mínima a utilizar para dados provenientes da detecção remota. Conclui-se que a detecção remota será a forma mais eficiente para a aquisição de dados a estas escalas.

A fotografia aérea, pelas possibilidades que fornece ao reunir elevadas resoluções espaciais $(0,25 \mathrm{~m}$, por exemplo) e temporais (considerando também que muitos destes países possuem acervos fotográficos de datas anteriores à divulgação comercial das imagens de satélite), e de apresentar resoluções espectrais que respondem às necessidades de identificação das questões urbanas, revela-se um meio versátil para a obtenção de dados sobre as cidades. Contudo, para os países em guerra, ou que tiveram guerras de longa duração (e são muitos em África!), a obtenção de fotografias aéreas pode constituir uma dificuldade difícil de ultrapassar.

As imagens provenientes de satélites como o IKONOS, OrbView3, Quickbird, de grande resolução geométrica, com pixel que pode atingir valores na ordem de $1 \mathrm{~m}$ em modo pancromático, embora ainda dispendiosas, como refere o estudo, podem satisfazer algumas necessidades em dados urbanos, principalmente porque as questões da resolução temporal apesar de importantes não são determinantes para o estudo deste fenómeno.

Por fim, destaque-se a vasta bibliografia (nomeadamente a disponível na Internet), à qual se vai fazendo menção ao longo de toda a obra, e que constitui uma excelente referência na aquisição e manipulação de informação geográfica para servir o desenvolvimento sustentável em África. 